\title{
Aggregation Prone Regions and Gatekeeping Residues in Protein Sequences ${ }^{\dagger}$
}

\author{
Jacinte Beerten $^{1,2}$, Joost Schymkowitz ${ }^{1,2, *}$ and Frederic Rousseau ${ }^{1,2, *}$ \\ ${ }^{I}$ VIB Switch Laboratory, VIB, Leuven, Belgium; ${ }^{2}$ Departement for Cellular and Molecular Medicine, University of Leu- \\ ven, Leuven, Belgium
}

\begin{abstract}
Most protein sequences contain one or several short aggregation prone regions (APR) that can nucleate protein aggregation. Under normal conditions these APRs are protected from aggregation by protein interactions or because they are buried in the hydrophobic core of native protein domains. However, mutation, physiological stress or age-related disregulation of protein homeostasis increases the probability that aggregation-nucleating regions become solvent exposed. Aggregation then results from the self-assembly of APRs into $\beta$-structured agglomerates that vary from small soluble oligomeric assemblies to large insoluble inclusions containing thousands of molecules. The functional effects of APR-driven aggregation are diverse and protein-specific leading to distinct disease phenotypes ranging from neurodegeneration to cancer. On a cellular and physiological level both wild type loss-of-function as well as aggregation-dependent gain-offunction effects have been shown to contribute to disease. Several molecular mechanism have been proposed to contribute to gain-of-function activity of protein aggregates including cellular membrane disregulation, saturation of the protein quality control machinery or the ability of aggregates to engage non-native interactions with proteins and nucleic acids. These different mechanisms will all, to some extent, contribute to gain-of-function as in essence they all contribute to the rewiring of the cellular interactome by aggregation-specific interactions, resulting for instance in the pronounced neurotoxicity of TDP43 aggregates by the sequestration of RNA molecules or the promotion of cell proliferation by the entrapment of homologous tumor suppressor proteins in p53 aggregates in cancer. In this review we discuss the mechanism of APR driven aggregation and how APRs contribute to modifying the cellular interactome by recruiting both misfolded as well as active proteins thereby inhibiting or activating specific cellular functions. Finally, we discuss the ubiquity of APRs in protein sequences and how selective pressure shaped protein sequences to minimize APR aggregation.
\end{abstract}

Keywords: Protein aggregation, beta-structure, aggregation prone region (APR), gatekeeper, amyloid.

\section{INTRODUCTION}

Protein aggregation is a process that has been recognized for a long time as heat coagulation was used to identify the proteinaceous nature of biological material since before 1838 when Berzelius first coined the term 'protein'. In 1935 Astbury determined the X-ray diffraction pattern of boiled egg white, for the first time showing that aggregated protein adopts an extended $\beta$-structured conformation [1], leading Perutz to recognize the conformational nature of aggregation in an article entitled 'Unboiling an egg", published in Discovery in 1940. Following Anfinsen's work on protein folding, protein aggregation was soon recognized to be a protein misfolding reaction competing with native protein folding [2-4], which is favoured by increasing protein concentration $[5,6]$. In recent years, the mechanistic details of this competition are emerging in several studies where partialy folded intermediates en-route to the native state were identified,

\footnotetext{
*Address correspondence to these authors at the VIB Switch Laboratory, Departement for Cellular and Molecular Medicine, Katholieke Universiteit Leuven, Campus Gasthuisberg O\&N1, Herestraat 49, 3000 Leuven, Belgium; Tel: +32 16 372570; E-mails: joost.schymkowitz@switch.vibkuleuven.be; frederic.rousseau@switch.vib-kuleuven.be
}

$\dagger$ This article is published as part of a themed issue on Protein Misfolding in Conformational Disorders, Guest Edited by Cláudio M. Gomes (ITQB/UNL). which alternatively to proper folding could also form nonnative interactions with similar molecules to give rise to the aggregation nucleus $[7,8]$. Since its discovery, protein aggregation has been associated to human disease and to inclusion body formation in the context of recombinant protein production. Both pathogenic deposits and recombinant inclusion bodies are highly enriched in one particular protein, suggesting the underlying aggregation mechanism is selective and specific [9-12]. In its most ordered form, protein aggregation gives rise to a fibrous deposit reminiscent of amylose, which have hence been called amyloid fibrils [13]. Interestingly, the nanostructures that are amyloid protein aggregates are also employed by nature, which e.g. exploits these microscopic wires for their tensile strength and adhesiveness, most famously perhaps as spider silk [14-16]. Other examples include the chorion protein, which contributes to the mechanical strength of the insect egg shell or the hydrophobins, which are used as a water repellent by filamentous fungi [17]. Last, but not least, amyloid fibrils are increasingly being researched as a source of novel biosynthetic nanomaterials [18].

\section{PROTEIN AGGREGATION IS A SELECTIVE PROC- ESS DRIVEN BY APRs}

A growing body of theoretical and experimental data suggests the specific nature of protein aggregation is driven 
by interaction of short aggregation prone polypeptide segments with specific amino acid composition [19, 20], further termed Aggregation Prone Regions or APRs for short. These aggregation nucleating segments are usually composed of 515 successively placed hydrophobic amino acids of low net charge that have been shown to constitute a sufficient and necessary requirement for protein aggregation [21-24]. Indeed grafting an APR on an otherwise non-aggregating protein scaffold is sufficient to induce aggregation [24, 25]. Although most proteins possess one or several APRs within their sequence [26, 27], these are generally buried in the hydrophobic core [28] or protein interaction sites [29, 30] and are thereby protected from aggregation. Solvent exposure of these aggregation prone segments in the event of transient breathing motions or protein unfolding $[31,32]$ initiates intermolecular association of APRs by $\beta$-strand interaction, thereby assembling APRs into $\beta$-sheet containing protein aggregates that adopt macromolecular morphologies ranging from amorphous assemblies to highly ordered amyloid fibrils Fig. (1) $[33,34]$. The intricasies of the underlying energy landscapes are being revealed by a number of experimental and theoretical approaches $[35,36]$. These intermolecular interactions between APRs mediating $\beta$-sheet structure are sequence dependent, resulting in a bias towards selfassociation over hetero-assembly [9, 12]. For example, cross-seeding of amyloid fibril formation between islet Amyloid polypeptide (IAPP) and the Alzheimer $\beta$-peptide $(A \beta)$ is very inefficient compared to self seeding of each peptide, although both the peptides share $70 \%$ sequence similarity in the aggregation nucleating cores [37]. Similarly, scrambled or reversed versions of the IAPP peptides do not cross-seed with each other or the wild type sequence, confirming position dependence beyond mere sequence composition [37].

\section{STRUCTURE AND SEQUENCE OF APRs}

The aggregation tendency of a peptide segment correlates with hydrophobicity and beta-sheet propensity and is favoured by a low net charge [38, 39]. As hydrophobicity and $\beta$-sheet propensity scales are available for all amino-acids, these biophysical correlations can be converted to sequencespecific $\beta$-aggregation prediction algorithms. The first algorithm built on these principles was the statistical thermodynamics algorithm TANGO [20] that, given the amino acid sequence of a protein, accurately locates beta-aggregation nucleating regions. Subsequently, alternative prediction algorithms to TANGO were developed (for a historic overview, see Fig. 2), that utilize similar amino acid characteristics such as hydrophobicity, beta propensity, packing density, charge constraints or derivations and combinations thereof [40-47]. A comprehensive review of APR detection methods is beyond the scope of the current manuscript, but excellent overviews can be found elsewhere [48-53].

The underlying rationale for this way of detecting aggregation prone regions (APRs) is the hydrophobic betastructure adopted by these sequences in the final aggregate or amyloid fibril. Recently, high resolution structural studies of amyloid fibrils derived from a number of such peptides, by both Nuclear Magnetic Resonance and microcrystal x-ray diffraction, confirmed the basic cross-beta concept $[13,54-$ 60]. However, significant variation is observed between the different structures, in terms of side chain packing, intermolecular distance and degree of regularity [21], revealing the molecular basis of the structural polymorphism observed in aggregates [61]. The essential feature is that of so-called steric zippers, where the sidechains of independently formed beta-sheets are held to together by interdigitation and close packing [56]. Based on theoretical considerations, Eisenberg proposed that eight different structural classes of such zipper arrangements would be possible for the cross-beta spine [56], and for all but one of these we have experimentally observed cases [62]. In addition, more complex structures have also been observed, such as the amyloid fibrils of the Alzheimer beta peptide, in which each molecule contributes two $\beta$-strands, connected by a loop region to the final structure [58]. Importantly, similar structures have been observed in cellular inclusion bodies, showing that the basic pattern applies in vivo [63].

A second generation of APR predictors exploits this new wealth of structural information directly by employing homology modelling techniques based on the high resolution structural data [27,64], or by combining position-specific scoring matrices with such homology modelling based scores [19] Fig. (2). These predictors tend to be more specific for the amyloid fibril structure than earlier predictors, which predicted amyloid and amorphous beta-aggregation alike $[19,65]$. Last but not least, the high resolution structural information is now being exploited to design sequence specific aggregation inhibitors that are designed to cap and inhibit the aggregation potential of APRs $[66,67]$.
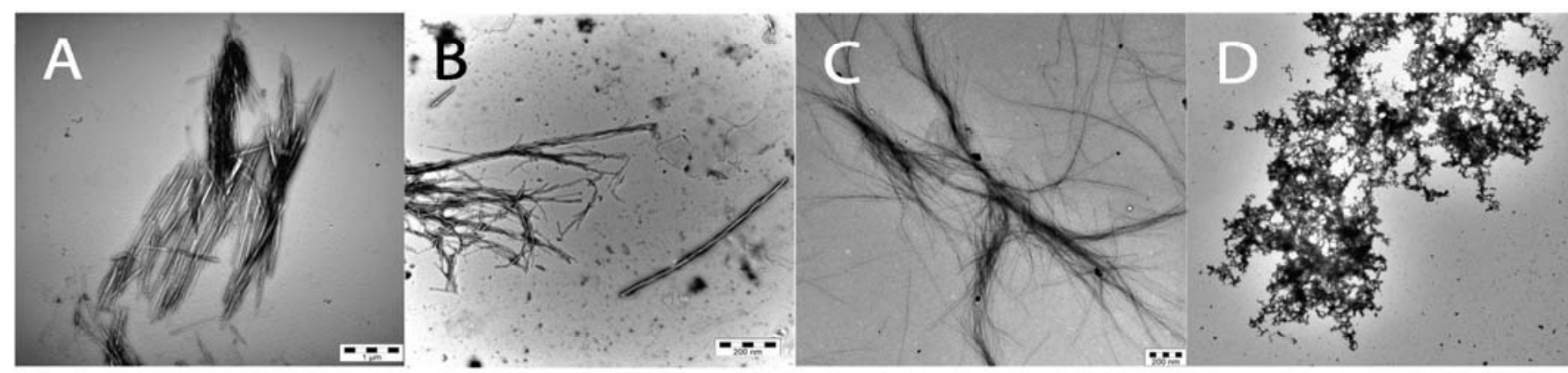

Fig. (1). Transmission Electron Microscopy images of peptides corresponding to aggregation prone regions of selected proteins display a wide range of morphologies, from highly ordered straight (A) or (B) twisted fibrils, over various degrees of order $(\mathbf{C})$ to completely amorphous structures (D). 

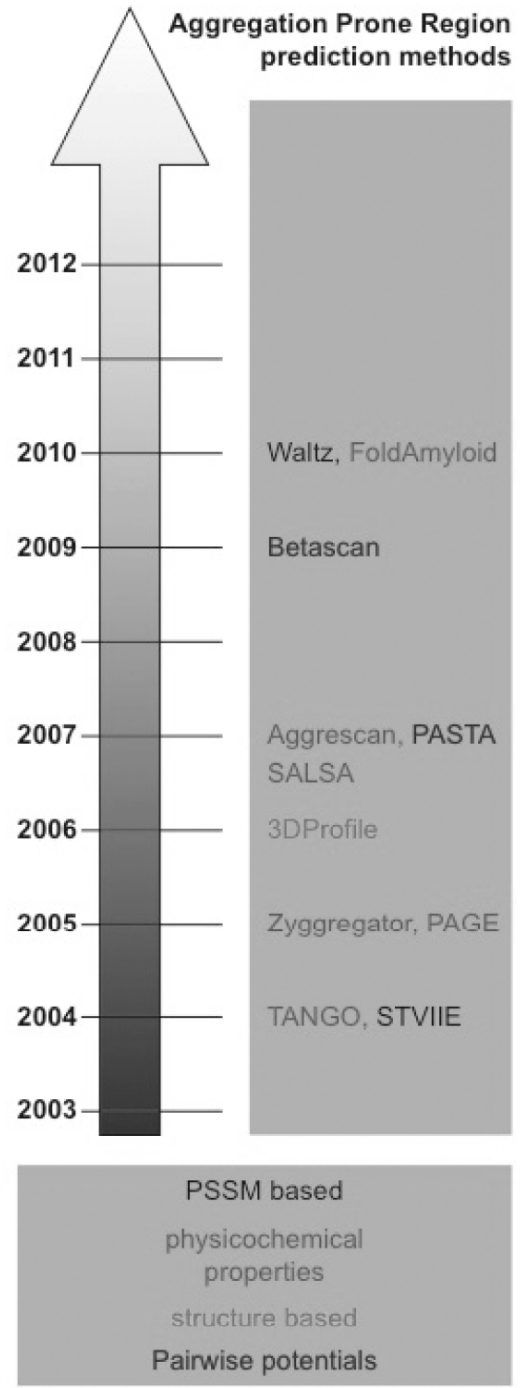

Fig. (2). Historic overview of some well known APR prediction algorithms: TANGO [20], the STVIIE sequence pattern [139], Zyggregator [40], PAGE [140], 3DProfile [27, 64], SALSA [47], Aggrescan [141], PASTA [142], Betascan [143], AmylPred [144], Waltz [19] and FoldAmyloid [145].

Prion proteins occupy a particular niche in the sequence space of amyloids: these polar sequences are highly enriched in asparagine and glutamine residues, and these residues seem to generate a balance between amyloid formation, promoted by asparagine, and intrinsic disorder, promoted by glutamine [68, 69]. The effect of these two residues is so strong that a search of the yeast genome for regions with high $\mathrm{Q} / \mathrm{N}$ content lead to discovery of more than 10 novel yeast prions [70] and more recently, Toombs et al. demonstrated that the general principle could be turned in a high accurate prion-prediction algorithm [71].

\section{STRUCTURAL TRIGGERS OF AGGREGATION}

Using APR prediction algorithms on protein domain databases such as SCOP or on full proteome sets [26, 27] reveals that about $18 \%$ on average of the residues from globular domain folds are within aggregation prone regions, irrespective of whether the protein has an all- $\alpha$, all $\beta$ or mixed $\alpha / \beta$ topology, while intrinsically disordered proteins on average only have about $8 \%$ of residues within aggregation prone regions. Whereas most protein domains contain one or more APRs only about 5\% of globular domains are completely devoid of APRs whereas $40 \%$ of unstructured domains are devoid of APRs, suggesting a strong protective effect of globular structure to suppress APRs [22]. This is in line with the observation that the APRs constitute the most stable regions of the hydrophobic core of the native protein $[72,73]$ and with earlier work into the mechanism of protein aggregation showed that aggregation often proceeds from partially folded intermediates [39, 74], consistent with the observation that APRs are protected from the solvent under native conditions by their incorporation in the globular fold of the functional protein. This then raises the question what causes protein to adopt conformations that allow APRs to nucleate aggregation under near-native conditions. An obvious mechanism is the thermodynamic destabilisation of the native structure by genetic mutation [75], post-translation modication [76] (such as tryptophan oxidation) or loss of translational fidelity $[77,78]$, which can lead to an increased population of the denatured state of the protein [79]. However, more recently it became clear that aggregation does not require the polypeptide to cross the major energy barrier for unfolding, but rather that local fluctuations in structure can sufficiently expose APRs to facilitate aggregation nucleation [33]. Eg, recently the near-native but aggregation prone conformations of acyl phosphatase from Drosophila were mapped experimentally, revealing changes in surface charge distrubitions, solvent exposure of hydrophobic amino acids and alterations to the topology of the elements of secondary structure [32]. In the Anthrax Protective Antigen protein, a near-surface APR was shown to initate the aggregation reaction [80]. Another striking example is $\alpha$-Chymotrypsinogen A, where aggregation is initiated through some major structural remodelling of some near-surface APRs without affecting the overal fold [81]. Such subtle fluctuations can easily be caused by protein non-intrinsic factors which then cause misfolding and aggregation in perfectly translated polypeptides with wild type sequences. This is often observed when proteins are employed for research, therapy or industrial applications, when they are expected to withstand artificial conditions for which evolution has poorly equipped them [82]. Inside the cellular context however, it is change in the proteostatic capacity of the cell that is the key factor, ie changes in the balance between protein synthesis, (re)folding and degradation, which has been extensively reviewed elsewhere [83-85].

\section{AGGREGATION-SPECIFIC INTERACTOMES AND GAIN-OF-FUNCTION}

The functional consquences of protein aggregation include loss of function effect as well as gain of novel functions. Although initially gain of function activity was mostly restricted to cytotoxicity, it recently became clear with aggregates of the tumor suppressor protein p53 that the functional consequences can be much more diverse, as in the case of p53 aggregation actually promotes cellular growth [86]. The molecular mechanisms by which downstream effects of protein aggregation take place are multiple, but two main categories can be discerned: (1) Sequestration of additional 

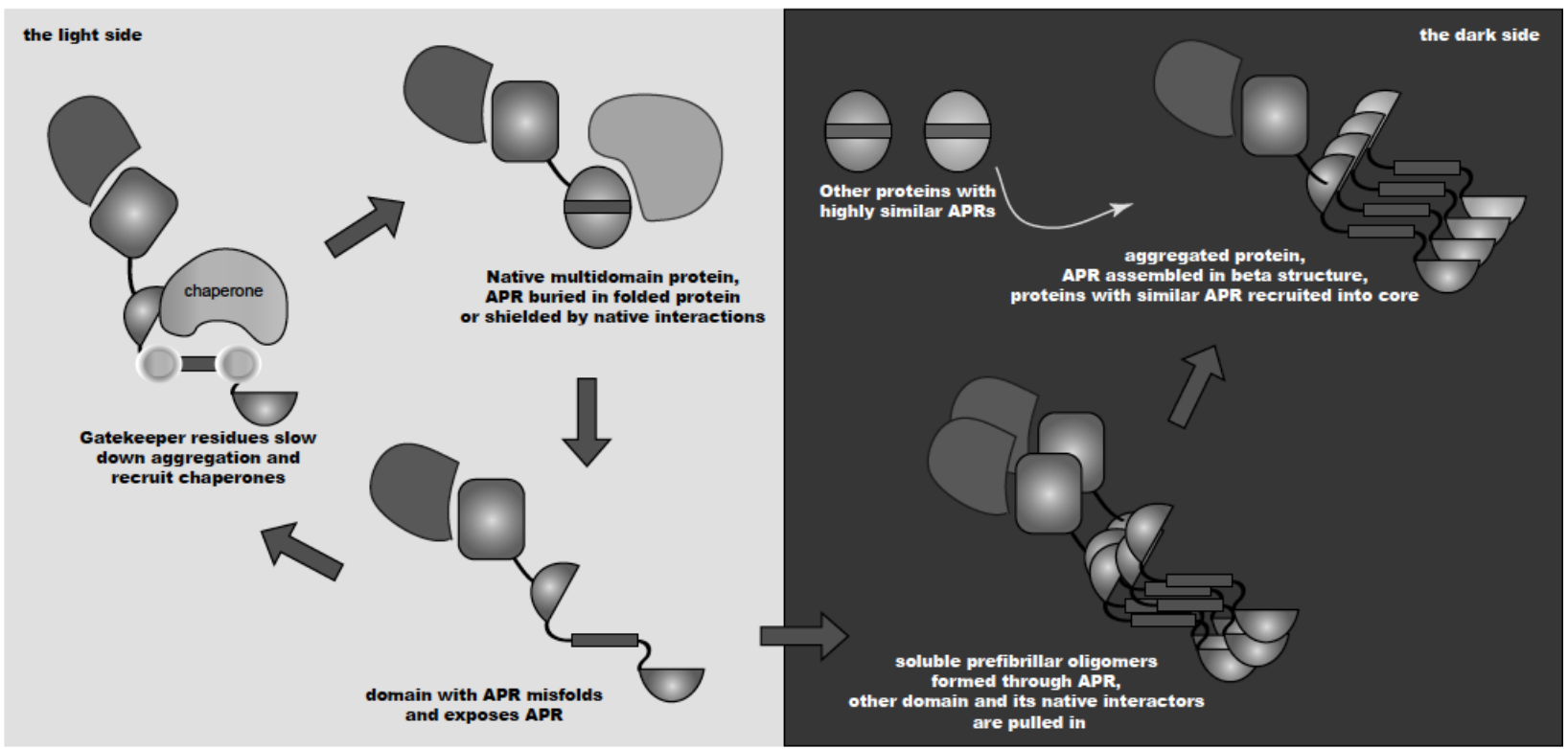

Fig. (3). Schematic overview of some of the main consequences of- and cellular strategies against protein aggregation.

cellular factors [86], which includes the overwhelming of the proteostatic machinery through depletion of chaperones [87], and (2) Disruption of the structural integrity of the cell through interaction with and perturbation of cellular membranes $[88,89]$ or the cytoskeleton $[90,91]$. Both classes of mechanisms are not mutually exclusive and both aspects may contribute to a different extent to the functional consequences of aggregation of particular proteins. A unifying factor is the observation that it is not the mature aggregates that mediate gain of function effects but the smaller soluble aggregates also known as prefibrillar oligomers [62]. For example in Alzheimer Disease, several of these species have been identified, including dimmers [92], trimers [93] and $A \beta$ species with a molecular weight of $56 \mathrm{kDa}$ [94] to $\mathrm{A} \beta-$ derived diffusible ligands (ADDLs)[95] and annular protofibrils [96] in potent neurotoxic fractions. Recently, the first high resolution structure of an oligomeric form of an amyloid forming peptide derived from $\alpha \mathrm{B}$ crystallin was determined, revealing a beta-barrel configuration [97]. Since a single conformationaly specific antibody specifically recognises the oligomeric conformation of many proteins, independent of sequence, it is tempting to speculate that a similar barrel structure will be found for many other diseaseassociated oligomers [98].

Once the APRs start assembling into intermolecular betastructures, the domain in which they reside is thought to be mostly unfolded, causing the loss of its function, but other domains in the protein need not be affected by the aggregation and can retain their functional fold. This is for example the case for a designed amyloid of an RNAse A protein, in which the domains that are peripheral to the amyloid spine (formed by the APR) retain their globular fold [99]. A similar scenario was proposed for amyloid fibrils of the yeast prion Ure2, which also leads to the assembly of functionally intact protein into the fibrils $[100,101]$. Assembly of functional protein domains into uncontrolled aggregates presents the cell with a dramatic form of disregulation, which was beautifully illustrated with the case of TDP43, which is found to form toxic aggregates in the motor neurons of a large fraction of patients with Amyotrophic Lateral Sclerosis (ALS) [102-104]: in this protein, the aggregation is nucleated by APRs in it carboxyterminal domain [105], but the toxicity of these aggregates hinges on the presence of a central folded RNA-binding domain in the aggregates [106]. Since this TDP-43 RNA interaction domain has binding sites within a third of all mouse and human mRNAs, sequestration of RNAs in the aggregation is likely to be the key mechanism mediating neurotoxicity [107].

Finally, the case of p53 illustrates another form of sequestration, this time by assembly of highly similar APRs into the beta-spine of the mixed aggregate. Although wildtype $\mathrm{p} 53$ does not interact with $\mathrm{p} 63$ and $\mathrm{p} 73$, it was known that mutant p53 binds to p63 and p73 and inhibits their tumor suppressive functions $[108,109]$. We recently demonstrated that the inactivation of $\mathrm{p} 63$ and $\mathrm{p} 73$ by mutant $\mathrm{p} 53$ is determined by a specific APR called p53 $\beta$ in its DNAbinding domain that becomes exposed in mutant $\mathrm{p} 53$. Association of $\mathrm{p} 53 \beta$ with the homologous sequences in WT $\mathrm{p} 53$, p63 and p73 results in mutant p53 induced aggregation and inactivation of both WT p53 and its paralogues [110].

\section{CELLULAR MECHANISMS AGAINST APR AG- GREGATION}

Protein aggregation is deleterious for the activity of the affected protein but often also affects cellular function or an organism at a systemic level. Given the strong selective disadvantage of misfolding and aggregation [111] it could seem surprising that the vast majority of proteins in any proteome possess at least one and generally several APRs. This strongly suggests that the presence of APR is somehow associated to the function and folding of proteins and cannot therefore easily be selected against [22]. Computational analysis has shown that the molecular basis of this is the fact that the same basic forces drive protein aggregation and folding $[51,112,113]$, although the proportional relevance of individual components such as hydrophobicity and hydrogen 
bonding may differ between globular and fibrillar structures [114]. As a result, the only group of polypeptides with a reduced overall aggregation propensity are the intrinsically unstructured proteins (IDPs)[22].

Shortly after the publication of the first APR prediction algorithm, it was employed to study the aggregation load of 28 proteomes from different kingdoms of life, which lead to the first clear statistical evidence that evolutionary pressure to reduce protein aggregation pervades all known polypeptide sequences [115]. Later, this was confirmed in other studies to be independent of method employed $[116,117]$ or the proteomes studied [118-120]. The key pattern that emerged is that of so-called aggregation gatekeepers flanking APRs [115]. This term was first coined during the study of the folding mechanism of CI2 [121] and S6 [122, 123] to describe residues that keep the protein on the productive folding pathway to the native state. In the context of APRs, the gatekeeper term is used to indicate amino acids that disrupt the aggregating hydrophobic stretches and keep the aggregation propensity of the local sequence in check. A major component in this effect is the repulsive effect of introducing charged residues (Arg, Lys, Asp, Glu), but among these aggregation is penalised more effectively in an entropic manner [124] with the placement of large and flexible side-chains like Arg of Lys. Finally, aggregation can be controlled using residues that are incompatible with the beta-structure of aggregates, as is the case for proline and perhaps to a lesser extend also glycine $[125,126]$. Interestingly, the effect of proline is stereochemically selective as it is only effective at the N-terminal side of the APR [111].

The relevance of the statistical enrichement of gatekeeper residues at positions flanking APRs was confirmed by several independent studies. First, the selective pressure against aggregation is especially pronounced in proteins with an essential cellular function $[118,127,128]$. Second, it was established that mutations that disrupt the gatekeeper pattern occur more frequently in disease-associated mutations than in polymorphisms [119]. Third, a host of experimental studies found the gatekeeper residues to be essential determinants of aggregation behaviour of the protein of interest. Eg. gatekeeper residues have been shown to modulate in vivo amyloid fibril formation by the bacterial curli protein [129], gatekeepers were shown to affect the aggregation rate of the SH3 domain of the PI3K protein [120] and that of the Parkinson disease-associated mutant of alphasynuclein A51T [130] and finally, gatekeeper residues modulated the in cellulo aggregation of the tumor suppressor p53 [86]. Further, it was independently shown that gatekeeper residues are not necessarily required to mediate native folding, but rather, specifically prevent aggregation from the unfolded state [131] (by the mechanisms discussed above such as charge repulsion). Moreover, gatekeepers participate or at least facilitate recognition of APRs by molecular chaperones, such as Hsp70, preventing intermolecular assembly and nucleation of aggregation [132]. Interestingly, we found that gatekeeper residues of an aggregating protein overexpressed in E.coli affected bacterial fitness by modulating the proteostatic network in an attempt to match protein expression to the toxicity of the aggregation process [111].
The final line of support for the notion that the gatekeeper pattern is an essential feature of protein architecture, comes from the study of groups of proteins in particular danger of aggregation such as proteins having a long lifetime or which are expressed at high levels. In several independent studies of these proteins it was observed that the gatekeeper pattern is evolutionarily enhanced. Proteins at risk for aggregation can easily be identified by basic considerations about the kinetics and thermodynamics of the protein aggregation reaction:

(A) Protein aggregation is a nucleation-growth phenomenon with a lag phase during which stable nuclei need to form, followed by a rapid growth phase. Thus, in short lived proteins aggregation can be prevented by their natural elimination within the lag-phase of aggregation, but long lived proteins need to be better equipped to avoid aggregation during long times scale. Accordingly we did observe that proteins with a long biological life time show a reduction in their intrinsic aggregation propensity [72].

(B) Moreover, both the rate and the extent of aggregation is strongly increased with increasing protein concentration. As a result, a more pronounced pressure to minimize aggregation is noticed in proteins with a high expression level [133], or - even more clearly - in proteins with a high abundance [134].

(C) Last but not least, the APR model of aggregation also implies that the aggregates bury significantly less hydrophobic surface area than would be the case in a globularly folded protein, since only a short stretch of the polypeptide is involved in the actual aggregate core. The result of this is that the heat capacity $\left(\Delta c_{p}\right)$ of the aggregates will be lower than that of folded proteins, so the native state is destabilised more per degree of temperature than the aggregated state, or in other words: increases in temperature favour aggregation over native folding. Consistent with this, in thermophilic proteins both the gatekeeper pattern and the burial of aggregating sequences are more pronounced than in mesophilic proteins [135].

Evolutionary elimination of aggregation nucleating regions is ultimately limited by the fact that protein function is the primary selection criterion. Therefore, when aggregation prone sequences do persist, they are usually found in functionally important regions of proteins, where mutations would interfere with function, such as the antigen complementation regions of antibodies [136], or protein-protein interaction regions in general $[137,138]$.

\section{CONCLUSION}

In summary, it is becoming clear from the recent developments in the field that protein aggregation is triggered by short aggregation prone regions or APR, that can nucleate aggregation by assembling into intermolecular betastructures. APRs occur with relatively high frequency in protein sequences because high hydrophobicity, high betasheet propensity and low net charge are architectural requirements for the proper folding of an hydrophobic core in globular protein domains but these conditions unfortunately also favor protein aggregation. In conditions where the stability of the native state is intact, the APRs are buried and 
thereby inert, but as soon as they become more exposed to the solvent, aggregation may be initiated. When aggregates are formed, they have a strong negative impact on cellular fitness, by sequestration of other cellular factors, by causing overload of the proteostatic machinery, by disruption of cellular membranes or by any combination of the above. Not surprisingly, there has been strong evolutionary pressure to minimize the aggregation propensity of APRs by the placement of aggregation gatekeeper residues at the positions directly flanking the APR. These act by slowing down the aggregation reaction in case the APR becomes solvent exposed, giving refolding another chance, as well as by increasing chaperone binding to the exposed hydrophobic region. However, protein structural and functional requirements limits the evolutionary pruning of APRs, and they do persist mainly in regions that are essential for either protein stability or for protein function, such as the hydrophobic core or active sites and protein-protein interaction sites.

\section{CONFLICT OF INTEREST}

The author(s) confirm that this article content has no conflicts of interest.

\section{ACKNOWLEDGEMENTS}

The VIB Switch Laboratory was supported by grants from the Flanders Institute for Biotechnology (VIB), the University of Leuven (KUL), the Funds for Scientific Research Flanders (FWO), the Flanders Institute for Science and Technology (IWT) and the Interuniversity Attraction Pole (IAP) Network from the Science Policy of the Federal Government of Belgium (Belspo).

\section{REFERENCES}

[1] Astbury, W. T.; Dickinson, S.; Bailey, K., The X-ray interpretation of denaturation and the structure of the seed globulins. Biochem $J$ 1935, 29 (10), 2351-2360 1.

[2] Jaenicke, R., Folding and association of proteins. Progress in biophysics and molecular biology 1987, 49 (2-3), 117-237.

[3] Zettlmeissl, G.; Rudolph, R.; Jaenicke, R., Reconstitution of lactic dehydrogenase. Noncovalent aggregation vs. reactivation. 1. Physical properties and kinetics of aggregation. Biochemistry 1979, $18(25), 5567-71$.

[4] Zettlmeissl, G.; Rudolph, R.; Jaenicke, R., Reconstitution of lactic dehydrogenase after acid dissociation. The yield of reactivation is determined by conformational rearrangements of the dissociated monomers. European journal of biochemistry / FEBS 1981, 121 (1), 169-75.

[5] Rudolph, R.; Zettlmeissl, G.; Jaenicke, R., Reconstitution of lactic dehydrogenase. Noncovalent aggregation vs. reactivation. 2. Reactivation of irreversibly denatured aggregates. Biochemistry 1979, $18(25), 5572-5$

[6] Goldberg, M. E.; Rudolph, R.; Jaenicke, R., A kinetic study of the competition between renaturation and aggregation during the refolding of denatured-reduced egg white lysozyme. Biochemistry 1991, 30 (11), 2790-7.

[7] Neudecker, P.; Robustelli, P.; Cavalli, A.; Walsh, P.; Lundstrom, P.; Zarrine-Afsar, A.; Sharpe, S.; Vendruscolo, M.; Kay, L. E., Structure of an intermediate state in protein folding and aggregation. Science 2012, 336 (6079), 362-6.

[8] Krobath, H.; Estacio, S. G.; Faisca, P. F.; Shakhnovich, E. I., Identification of a Conserved Aggregation-Prone Intermediate State in the Folding Pathways of Spc-SH3 Amyloidogenic Variants. $J$ Mol Biol 2012.

[9] Ren, P. H.; Lauckner, J. E.; Kachirskaia, I.; Heuser, J. E.; Melki, R.; Kopito, R. R., Cytoplasmic penetration and persistent infection of mammalian cells by polyglutamine aggregates. Nat Cell Biol 2009, 11 (2), 219-25.

[10] Rajan, R. S.; Kopito, R. R., Suppression of wild-type rhodopsin maturation by mutants linked to autosomal dominant retinitis pigmentosa. J Biol Chem 2005, 280 (2), 1284-91.

[11] Morell, M.; Bravo, R.; Espargaro, A.; Sisquella, X.; Aviles, F. X.; Fernandez-Busquets, X.; Ventura, S., Inclusion bodies: Specificity in their aggregation process and amyloid-like structure. Biochimica Et Biophysica Acta-Molecular Cell Research 2008, 1783 (10), $1815-1825$

[12] Rajan, R. S.; Illing, M. E.; Bence, N. F.; Kopito, R. R., Specificity in intracellular protein aggregation and inclusion body formation. Proc Natl Acad Sci U S A 2001, 98 (23), 13060-5.

[13] Serpell, L. C.; Sunde, M.; Blake, C. C., The molecular basis of amyloidosis. Cell Mol Life Sci 1997, 53 (11-12), 871-87.

[14] Otzen, D.; Nielsen, P. H., We find them here, we find them there: Functional bacterial amyloid. Cellular and Molecular Life Sciences 2008, 65 (6), 910-927.

[15] Fowler, D. M.; Koulov, A. V.; Alory-Jost, C.; Marks, M. S.; Balch, W. E.; Kelly, J. W., Functional amyloid formation within mam malian tissue. PLoS Biol 2006, 4 (1), e6.

[16] Chiti, F.; Dobson, C. M., Protein misfolding, functional amyloid, and human disease. Annual Review of Biochemistry 2006, 75, 333366.

[17] Iconomidou, V. A.; Hamodrakas, S. J., Natural protective amy loids. Curr Protein Pept Sci 2008, 9 (3), 291-309.

[18] Knowles, T. P.; Buehler, M. J., Nanomechanics of functional and pathological amyloid materials. Nature nanotechnology 2011, 6 (8), 469-79.

[19] Maurer-Stroh, S.; Debulpaep, M.; Kuemmerer, N.; de la Paz, M. L.; Martins, I. C.; Reumers, J.; Morris, K. L.; Copland, A.; Serpell, L.; Serrano, L.; Schymkowitz, J. W.; Rousseau, F., Exploring the sequence determinants of amyloid structure using position-specific scoring matrices. Nat Methods 2010, 7 (3), 237-42.

[20] Fernandez-Escamilla, A. M.; Rousseau, F.; Schymkowitz, J.; Serrano, L., Prediction of sequence-dependent and mutational effects on the aggregation of peptides and proteins. Nat Biotechnol 2004, 22 (10), 1302-6.

[21] Rousseau, F.; Schymkowitz, J.; Serrano, L., Protein aggregation and amyloidosis: confusion of the kinds? Curr Opin Struct Biol 2006, 16, 1-9.

[22] Linding, R.; Schymkowitz, J.; Rousseau, F.; Diella, F.; Serrano, L., A comparative study of the relationship between protein structure and beta-aggregation in globular and intrinsically disordered proteins. J Mol Biol 2004, 342 (1), 345-53.

[23] Esteras-Chopo, A.; Serrano, L.; de la Paz, M. L., The amyloid stretch hypothesis: Recruiting proteins toward the dark side. Proceedings of the National Academy of Sciences of the United States of America 2005, 102 (46), 16672-16677.

[24] Teng, P. K.; Eisenberg, D., Short protein segments can drive a nonfibrillizing protein into the amyloid state. Protein Eng Des Sel 2009, 22 (8), 531-6.

[25] Ventura, S.; Zurdo, J.; Narayanan, S.; Parreno, M.; Mangues, R.; Reif, B.; Chiti, F.; Giannoni, E.; Dobson, C. M.; Aviles, F. X.; Serrano, L., Short amino acid stretches can mediate amyloid formation in globular proteins: the Src homology 3 (SH3) case. Proc Natl Acad Sci U S A 2004, 101 (19), 7258-63.

[26] Rousseau, F.; Serrano, L.; Schymkowitz, J. W. H., How evolutionary pressure against protein aggregation shaped chaperone specificity. Journal of Molecular Biology 2006, 355 (5), 10371047.

[27] Goldschmidt, L.; Teng, P. K.; Riek, R.; Eisenberg, D., Identifying the amylome, proteins capable of forming amyloid-like fibrils. Proceedings of the National Academy of Sciences of the United States of America 2010, 107 (8), 3487-3492.

[28] Dobson, C. M., Protein folding and misfolding. Nature 2003, 426 (6968), 884-90.

[29] Masino, L.; Nicastro, G.; Calder, L.; Vendruscolo, M.; Pastore, A. Functional interactions as a survival strategy against abnormal aggregation. FASEB $J 2011$.

[30] Pastore, A.; Temussi, P. A., The two faces of Janus: functional interactions and protein aggregation. Curr Opin Struct Biol 2012, 22 (1), 30-7.

[31] Calamai, M.; Chiti, F.; Dobson, C. M., Amyloid fibril formation can proceed from different conformations of a partially unfolded protein. Biophys $J$ 2005, 89 (6), 4201-10. 
[32] De Simone, A.; Dhulesia, A.; Soldi, G.; Vendruscolo, M.; Hsu, S. T.; Chiti, F.; Dobson, C. M., Experimental free energy surfaces reveal the mechanisms of maintenance of protein solubility. Proc Natl Acad Sci U S A 2011, 108 (52), 21057-62.

[33] Chiti, F.; Dobson, C. M., Amyloid formation by globular proteins under native conditions. Nat Chem Biol 2009, 5 (1), 15-22.

[34] Luheshi, L. M.; Crowther, D. C.; Dobson, C. M., Protein misfol ding and disease: from the test tube to the organism. Current Opinion in Chemical Biology 2008, 12 (1), 25-31.

[35] Thirumalai, D.; Reddy, G.; Straub, J. E., Role of water in protein aggregation and amyloid polymorphism. Acc Chem Res 2012, 45 (1), 83-92.

[36] Straub, J. E.; Thirumalai, D., Toward a molecular theory of early and late events in monomer to amyloid fibril formation. Аnпиаl review of physical chemistry 2011, 62, 437-63.

[37] Sabate, R.; Espargaro, A.; de Groot, N. S.; Valle-Delgado, J. J.; Fernandez-Busquets, X.; Ventura, S., The Role of Protein Sequence and Amino Acid Composition in Amyloid Formation: Scrambling and Backward Reading of IAPP Amyloid Fibrils. $J$ Mol Biol 2010.

[38] Chiti, F.; Stefani, M.; Taddei, N.; Ramponi, G.; Dobson, C. M., Rationalization of the effects of mutations on peptide and protein aggregation rates. Nature 2003, 424 (6950), 805-8.

[39] Chiti, F.; Taddei, N.; Baroni, F.; Capanni, C.; Stefani, M.; Ramponi, G.; Dobson, C. M., Kinetic partitioning of protein folding and aggregation. Nat Struct Biol 2002, 9 (2), 137-43.

[40] Pawar, A. P.; Dubay, K. F.; Zurdo, J.; Chiti, F.; Vendruscolo, M.; Dobson, C. M., Prediction of "aggregation-prone" and "aggre gation-susceptible" regions in proteins associated with neuro degenerative diseases. J Mol Biol 2005, 350 (2), 379-92.

[41] Grover, A.; Dugar, D.; Kundu, B., Predicting alternate structure attainment and amyloidogenesis: a nonlinear signal analysis approach. Biochem Biophys Res Commun 2005, 338 (3), 1410-6.

[42] Sanchez de Groot, N.; Pallares, I.; Aviles, F. X.; Vendrell, J.; Ventura, S., Prediction of "hot spots" of aggregation in diseaselinked polypeptides. BMC Struct Biol 2005, 5, 18.

[43] Tartaglia, G. G.; Cavalli, A.; Pellarin, R.; Caflisch, A., Prediction of aggregation rate and aggregation-prone segments in polypeptide sequences. Protein Sci 2005, 14 (10), 2723-34.

[44] Galzitskaya, O. V.; Garbuzynskiy, S. O.; Lobanov, M. Y., Prediction of amyloidogenic and disordered regions in protein chains. PLoS Comput Biol 2006, 2 (12), e177.

[45] Saiki, M.; Konakahara, T.; Morii, H., Interaction-based evaluation of the propensity for amyloid formation with cross-beta structure. Biochem Biophys Res Commun 2006, 343 (4), 1262-71.

[46] Thompson, M. J.; Sievers, S. A.; Karanicolas, J.; Ivanova, M. I.; Baker, D.; Eisenberg, D., The 3D profile method for identifying fibril-forming segments of proteins. PNAS 2006, 103 (11), 4074-8.

[47] Zibaee, S.; Makin, O. S.; Goedert, M.; Serpell, L. C., A simple algorithm locates beta-strands in the amyloid fibril core of alphasynuclein, Abeta, and tau using the amino acid sequence alone. Protein Sci 2007, 16 (5), 906-18.

[48] Cellmer, T.; Bratko, D.; Prausnitz, J. M.; Blanch, H. W., Protein aggregation in silico. Trends in Biotechnology 2007, 25 (6), 254261.

[49] Agrawal, N. J.; Kumar, S.; Wang, X. L.; Helk, B.; Singh, S. K.; Trout, B. L., Aggregation in Protein-Based Biotherapeutics: Computational Studies and Tools to Identify Aggregation-Prone Regions. Journal of Pharmaceutical Sciences 2011, 100 (12), 5081-5095.

[50] Caflisch, A., Computational models for the prediction of polypeptide aggregation propensity. Current Opinion in Chemical Biology 2006, 10 (5), 437-444.

[51] Gsponer, J.; Vendruscolo, M., Theoretical approaches to protein aggregation. Protein and Peptide Letters 2006, 13 (3), 287-293.

[52] Roberts, C. J.; Das, T. K.; Sahin, E., Predicting solution aggre gation rates for therapeutic proteins: Approaches and challenges. International Journal of Pharmaceutics 2011, 418 (2), 318-333.

[53] Castillo, V.; Grana-Montes, R.; Sabate, R.; Ventura, S., Prediction of the aggregation propensity of proteins from the primary sequence: Aggregation properties of proteomes. Biotechnology Journal 2011, 6 (6), 674-685.

[54] Makin, O. S.; Atkins, E.; Sikorski, P.; Johansson, J.; Serpell, L. C., Molecular basis for amyloid fibril formation and stability. Proc Natl Acad Sci U S A 2005, 102 (2), 315-20.
[55] Nelson, R.; Sawaya, M. R.; Balbirnie, M.; Madsen, A. O.; Riekel, C.; Grothe, R.; Eisenberg, D., Structure of the cross-beta spine of amyloid-like fibrils. Nature 2005, 435 (7043), 773-8.

[56] Sawaya, M. R.; Sambashivan, S.; Nelson, R.; Ivanova, M. I.; Sievers, S. A.; Apostol, M. I.; Thompson, M. J.; Balbirnie, M.; Wiltzius, J. J.; McFarlane, H. T.; Madsen, A. O.; Riekel, C.; Eisenberg, D., Atomic structures of amyloid cross-beta spines reveal varied steric zippers. Nature 2007, 447 (7143), 453-7.

[57] Sachse, C.; Xu, C.; Wieligmann, K.; Diekmann, S.; Grigorieff, N.; Fandrich, M., Quaternary structure of a mature amyloid fibril from Alzheimer's abeta(1-40) Peptide. J Mol Biol 2006, 362 (2), 347-54.

[58] Jaroniec, C. P.; MacPhee, C. E.; Bajaj, V. S.; McMahon, M. T. Dobson, C. M.; Griffin, R. G., High-resolution molecular structure of a peptide in an amyloid fibril determined by magic angle spinning NMR spectroscopy. Proc Natl Acad Sci U S A 2004, 101 (3), 711-6.

[59] Ferguson, N.; Becker, J.; Tidow, H.; Tremmel, S.; Sharpe, T. D.; Krause, G.; Flinders, J.; Petrovich, M.; Berriman, J.; Oschkinat, H.; Fersht, A. R., General structural motifs of amyloid protofilaments. Proc Natl Acad Sci U S A 2006, 103 (44), 16248-53.

[60] Makin, O. S.; Serpell, L. C., Structures for amyloid fibrils. Febs $J$ 2005, 272 (23), 5950-61

[61] Colletier, J. P.; Laganowsky, A.; Landau, M.; Zhao, M. L.; Soriaga, A. B.; Goldschmidt, L.; Flot, D.; Cascio, D.; Sawaya, M. R.; Eisenberg, D., Molecular basis for amyloid-beta polymorphism. Proceedings of the National Academy of Sciences of the United States of America 2011, 108 (41), 16938-16943.

[62] Eisenberg, D.; Jucker, M., The amyloid state of proteins in human diseases. Cell 2012, 148 (6), 1188-203.

[63] Wang, L.; Maji, S. K.; Sawaya, M. R.; Eisenberg, D.; Riek, R. Bacterial inclusion bodies contain amyloid-like structure. Plos Biology 2008, 6 (8), 1791-1801.

[64] Thompson, M. J.; Sievers, S. A.; Karanicolas, J.; Ivanova, M. I.; Baker, D.; Eisenberg, D., The 3D profile method for identifying fibril-forming segments of proteins. Proc Natl Acad Sci US A 2006, 103 (11), 4074-8.

[65] Rousseau, F.; Schymkowitz, J.; Serrano, L., Protein aggregation and amyloidosis: confusion of the kinds? Current Opinion in Structural Biology 2006, 16 (1), 118-126.

[66] Sievers, S. A.; Karanicolas, J.; Chang, H. W.; Zhao, A.; Jiang, L.; Zirafi, O.; Stevens, J. T.; Munch, J.; Baker, D.; Eisenberg, D., Structure-based design of non-natural amino-acid inhibitors of amyloid fibril formation. Nature 2011, 475 (7354), 96-100.

[67] Landau, M.; Sawaya, M. R.; Faull, K. F.; Laganowsky, A.; Jiang, L.; Sievers, S. A.; Liu, J.; Barrio, J. R.; Eisenberg, D., Towards a pharmacophore for amyloid. PLoS Biol 2011, 9 (6), e1001080.

[68] Halfmann, R.; Alberti, S.; Krishnan, R.; Lyle, N.; O'Donnell, C. W.; King, O. D.; Berger, B.; Pappu, R. V.; Lindquist, S., Opposing Effects of Glutamine and Asparagine Govern Prion Formation by Intrinsically Disordered Proteins. Molecular cell 2011, 43 (1), 7284.

[69] Toombs, J. A.; McCarty, B. R.; Ross, E. D., Compositional determinants of prion formation in yeast. Mol Cell Biol 2010, 30 (1), 319-32.

[70] Alberti, S.; Halfmann, R.; King, O.; Kapila, A.; Lindquist, S., A systematic survey identifies prions and illuminates sequence features of prionogenic proteins. Cell 2009, 137 (1), 146-58.

[71] Toombs, J. A.; Petri, M.; Paul, K. R.; Kan, G. Y.; Ben-Hur, A.; Ross, E. D., De novo design of synthetic prion domains. Proc Natl Acad Sci U S A 2012, 109 (17), 6519-24.

[72] De Baets, G.; Reumers, J.; Delgado Blanco, J.; Dopazo, J.; Schymkowitz, J.; Rousseau, F., An Evolutionary Trade-Off between Protein Turnover Rate and Protein Aggregation Favors a Higher Aggregation Propensity in Fast Degrading Proteins. PLoS Comput Biol 2011, 7 (6), e1002090.

[73] Tartaglia, G. G.; Vendruscolo, M., Proteome-level interplay between folding and aggregation propensities of proteins. $J$ Mol Biol 2008, 402 (5), 919-28.

[74] Chiti, F.; Calamai, M.; Taddei, N.; Stefani, M.; Ramponi, G.; Dobson, C. M., Studies of the aggregation of mutant proteins in vitro provide insights into the genetics of amyloid diseases. Proceedings of the National Academy of Sciences of the United States of America 2002, 99, 16419-16426.

[75] Yue, P.; Li, Z.; Moult, J., Loss of protein structure stability as a major causative factor in monogenic disease. $J$ Mol Biol 2005, 353 (2), 459-73. 
[76] Squier, T. C., Oxidative stress and protein aggregation during biological aging. Experimental Gerontology 2001, 36 (9), 15391550 .

[77] Powers, E. T.; Balch, W. E., Costly mistakes: translational infidelity and protein homeostasis. Cell 2008, 134 (2), 204-6.

[78] Lee, J. W.; Beebe, K.; Nangle, L. A.; Jang, J.; Longo-Guess, C. M.; Cook, S. A.; Davisson, M. T.; Sundberg, J. P.; Schimmel, P.; Ackerman, S. L., Editing-defective tRNA synthetase causes protein misfolding and neurodegeneration. Nature 2006, 443 (7107), 50-5.

[79] Fersht, A. R.; Matouschek, A.; Serrano, L., The folding of an enzyme. I. Theory of protein engineering analysis of stability and pathway of protein folding. J Mol Biol 1992, 224 (3), 771-82.

[80] Ganesan, A.; Watkinson, A.; Moore, B. D., Biophysical charac terisation of thermal-induced precipitates of recombinant anthrax protective antigen: Evidence for kinetically trapped unfolding domains in solid-state. European journal of pharmaceutics and biopharmaceutics : official journal of Arbeitsgemeinschaft fur Pharmazeutische Verfahrenstechnik e.V 2012.

[81] Zhang, A.; Jordan, J. L.; Ivanova, M. I.; Weiss, W. F.; Roberts, C. J.; Fernandez, E. J., Molecular Level Insights into Thermally Induced alpha-Chymotrypsinogen A Amyloid Aggregation Mecha nism and Semiflexible Protofibril Morphology. Biochemistry 2010, 49 (49), 10553-10564.

[82] Cromwell, M. E.; Hilario, E.; Jacobson, F., Protein aggregation and bioprocessing. The AAPS journal 2006, 8 (3), E572-9.

[83] Powers, E. T.; Morimoto, R. I.; Dillin, A.; Kelly, J. W.; Balch, W. E., Biological and chemical approaches to diseases of proteostasis deficiency. Annual review of biochemistry 2009, 78, 959-91.

[84] Balch, W. E.; Morimoto, R. I.; Dillin, A.; Kelly, J. W., Adapting proteostasis for disease intervention. Science 2008, 319 (5865), 916-9.

[85] Hartl, F. U.; Bracher, A.; Hayer-Hartl, M., Molecular chaperones in protein folding and proteostasis. Nature 2011, 475 (7356), 324-32.

[86] Xu, J.; Reumers, J.; Couceiro, J. R.; De Smet, F.; Gallardo, R.; Rudyak, S.; Cornelis, A.; Rozenski, J.; Zwolinska, A.; Marine, J. C.; Lambrechts, D.; Suh, Y. A.; Rousseau, F.; Schymkowitz, J., Gain of function of mutant $\mathrm{p} 53$ by coaggregation with multiple tumor suppressors. Nature Chemical Biology 2011, 7 (5), 285-295.

[87] Olzscha, H.; Schermann, S. M.; Woerner, A. C.; Pinkert, S.; Hecht, M. H.; Tartaglia, G. G.; Vendruscolo, M.; Hayer-Hartl, M.; Hartl, F. U.; Vabulas, R. M., Amyloid-like aggregates sequester nume rous metastable proteins with essential cellular functions. Cell 2011, 144 (1), 67-78.

[88] Bucciantini, M.; Cecchi, C., Biological membranes as protein aggregation matrices and targets of amyloid toxicity. Methods $\mathrm{Mol}$ Biol 2011, 648, 231-43.

[89] Bucciantini, M.; Giannoni, E.; Chiti, F.; Baroni, F.; Formigli, L.; Zurdo, J.; Taddei, N.; Ramponi, G.; Dobson, C. M.; Stefani, M., Inherent toxicity of aggregates implies a common mechanism for protein misfolding diseases. Nature 2002, 416 (6880), 507-11.

[90] Ganusova, E. E.; Ozolins, L. N.; Bhagat, S.; Newnam, G. P.; Wegrzyn, R. D.; Sherman, M. Y.; Chernoff, Y. O., Modulation of prion formation, aggregation, and toxicity by the actin cytoskeleton in yeast. Mol Cell Biol 2006, 26 (2), 617-29.

[91] Mukrasch, M. D.; von Bergen, M.; Biernat, J.; Fischer, D.; Griesinger, C.; Mandelkow, E.; Zweckstetter, M., The "jaws" of the tau-microtubule interaction. $J$ Biol Chem 2007, 282 (16), 12230-9.

[92] Shankar, G. M.; Li, S.; Mehta, T. H.; Garcia-Munoz, A.; Shepardson, N. E.; Smith, I.; Brett, F. M.; Farrell, M. A.; Rowan, M. J.; Lemere, C. A.; Regan, C. M.; Walsh, D. M.; Sabatini, B. L.; Selkoe, D. J., Amyloid-beta protein dimers isolated directly from Alzheimer's brains impair synaptic plasticity and memory. Nat Med 2008, 14 (8), 837-42.

[93] Townsend, M.; Shankar, G. M.; Mehta, T.; Walsh, D. M.; Selkoe, D. J., Effects of secreted oligomers of amyloid beta-protein on hippocampal synaptic plasticity: a potent role for trimers. $J$ Physiol 2006, 572 (Pt 2), 477-92.

[94] Lesne, S.; Koh, M. T.; Kotilinek, L.; Kayed, R.; Glabe, C. G.; Yang, A.; Gallagher, M.; Ashe, K. H., A specific amyloid-beta protein assembly in the brain impairs memory. Nature 2006, 440 (7082), 352-7.

[95] Gong, Y.; Chang, L.; Viola, K. L.; Lacor, P. N.; Lambert, M. P.; Finch, C. E.; Krafft, G. A.; Klein, W. L., Alzheimer's diseaseaffected brain: presence of oligomeric A beta ligands (ADDLs) suggests a molecular basis for reversible memory loss. Proc Natl Acad Sci U S A 2003, 100 (18), 10417-22.
[96] Kayed, R.; Pensalfini, A.; Margol, L.; Sokolov, Y.; Sarsoza, F.; Head, E.; Hall, J.; Glabe, C., Annular protofibrils are a structurally and functionally distinct type of amyloid oligomer. J Biol Chem 2008.

[97] Laganowsky, A.; Liu, C.; Sawaya, M. R.; Whitelegge, J. P.; Park, J.; Zhao, M.; Pensalfini, A.; Soriaga, A. B.; Landau, M.; Teng, P. K.; Cascio, D.; Glabe, C.; Eisenberg, D., Atomic view of a toxic amyloid small oligomer. Science 2012, 335 (6073), 1228-31.

[98] Kayed, R.; Head, E.; Thompson, J. L.; McIntire, T. M.; Milton, S. C.; Cotman, C. W.; Glabe, C. G., Common structure of soluble amyloid oligomers implies common mechanism of pathogenesis. Science 2003, 300 (5618), 486-9.

[99] Sambashivan, S.; Liu, Y.; Sawaya, M. R.; Gingery, M.; Eisenberg, D., Amyloid-like fibrils of ribonuclease A with three-dimensional domain-swapped and native-like structure. Nature 2005, 437 (7056), 266-9.

[100] Bousset, L.; Briki, F.; Doucet, J.; Melki, R., The native-like conformation of Ure2p in fibrils assembled under physiologically relevant conditions switches to an amyloid-like conformation upon heat-treatment of the fibrils. $J$ Struct Biol 2003, 141 (2), 132-42.

[101] Bousset, L.; Thomson, N. H.; Radford, S. E.; Melki, R., The yeast prion Ure2p retains its native alpha-helical conformation upon assembly into protein fibrils in vitro. Embo $J$ 2002, 21 (12), 290311.

[102] Pikkarainen, M.; Hartikainen, P.; Alafuzoff, I., Ubiquitinated p62positive, TDP-43-negative inclusions in cerebellum in fronto temporal lobar degeneration with TAR DNA binding protein 43 . Neuropathology : official journal of the Japanese Society of Neuropathology 2010, 30 (2), 197-9.

[103] Neumann, M.; Sampathu, D. M.; Kwong, L. K.; Truax, A. C.; Micsenyi, M. C.; Chou, T. T.; Bruce, J.; Schuck, T.; Grossman, M.; Clark, C. M.; McCluskey, L. F.; Miller, B. L.; Masliah, E.; Mackenzie, I. R.; Feldman, H.; Feiden, W.; Kretzschmar, H. A.; Trojanowski, J. Q.; Lee, V. M., Ubiquitinated TDP-43 in fronto temporal lobar degeneration and amyotrophic lateral sclerosis. Science 2006, 314 (5796), 130-3.

[104] Arai, T.; Hasegawa, M.; Akiyama, H.; Ikeda, K.; Nonaka, T.; Mori, H.; Mann, D.; Tsuchiya, K.; Yoshida, M.; Hashizume, Y.; Oda, T., TDP-43 is a component of ubiquitin-positive tau-negative inclu sions in frontotemporal lobar degeneration and amyotrophic lateral sclerosis. Biochem Biophys Res Commun 2006, 351 (3), 602-11.

[105] Yang, C.; Tan, W.; Whittle, C.; Qiu, L.; Cao, L.; Akbarian, S.; Xu, Z., The C-Terminal TDP-43 Fragments Have a High Aggregation Propensity and Harm Neurons by a Dominant-Negative Mecha nism. PLoS One 2010, 5 (12), e15878.

[106] Johnson, B. S.; McCaffery, J. M.; Lindquist, S.; Gitler, A. D., A yeast TDP-43 proteinopathy model: Exploring the molecular determinants of TDP-43 aggregation and cellular toxicity. Proc Natl Acad Sci U S A 2008, 105 (17), 6439-44.

[107] Da Cruz, S.; Cleveland, D. W., Understanding the role of TDP-43 and FUS/TLS in ALS and beyond. Current opinion in neuro biology 2011, 21 (6), 904-19.

[108] Li, Y.; Prives, C., Are interactions with p63 and p73 involved in mutant p53 gain of oncogenic function? Oncogene 2007, 26 (15), 2220-5.

[109] Melino, G., p63 is a suppressor of tumorigenesis and metastasis interacting with mutant $\mathrm{p} 53$. Cell death and differentiation 2011, $18(9), 1487-1499$.

[110] Xu, J.; Reumers, J.; Couceiro, J. R.; De Smet, F.; Gallardo, R.; Rudyak, S.; Cornelis, A.; Rozenski, J.; Zwolinska, A.; Marine, J. C.; Lambrechts, D.; Suh, Y. A.; Rousseau, F.; Schymkowitz, J., Gain of function of mutant $\mathrm{p} 53$ by coaggregation with multiple tumor suppressors. Nat Chem Biol 2011, 7 (5), 285-95.

[111] Beerten, J.; Jonckheere, W.; Rudyak, S.; Xu, J.; Wilkinson, H.; De Smet, F.; Schymkowitz, J.; Rousseau, F., Aggregation gatekeepers modulate protein homeostasis of aggregating sequences and affect bacterial fitness. Protein Eng Des Sel 2012.

[112] Eisenberg, D.; Nelson, R.; Sawaya, M. R.; Balbirnie, M.; Sambashivan, S.; Ivanova, M. I.; Madsen, A. O.; Riekel, C., The structural biology of protein aggregation diseases: Fundamental questions and some answers. Acc Chem Res 2006, 39 (9), 568-75.

[113] Bratko, D.; Cellmer, T.; Prausnitz, J. M.; Blanch, H. W., Molecular simulation of protein aggregation. Biotechnology and Bioengi neering 2007, 96 (1), 1-8.

[114] Fitzpatrick, A. W.; Knowles, T. P.; Waudby, C. A.; Vendruscolo, M.; Dobson, C. M., Inversion of the balance between hydrophobic 
and hydrogen bonding interactions in protein folding and aggregation. PLoS Comput Biol 2011, 7 (10), e1002169.

[115] Rousseau, F.; Serrano, L.; Schymkowitz, J. W., How evolutionary pressure against protein aggregation shaped chaperone specificity. J Mol Biol 2006, 355 (5), 1037-47.

[116] Monsellier, E.; Chiti, F., Prevention of amyloid-like aggregation as a driving force of protein evolution. EMBO reports 2007, 8 (8), 737-42.

[117] Monsellier, E.; Ramazzotti, M.; de Laureto, P. P.; Tartaglia, G. G.; Taddei, N.; Fontana, A.; Vendruscolo, M.; Chiti, F., The distribution of residues in a polypeptide sequence is a determinant of aggregation optimized by evolution. Biophysical Journal 2007, 93 (12), 4382-4391.

[118] de Groot, N. S.; Ventura, S., Protein aggregation profile of the bacterial cytosol. PLoS One 2010, 5 (2), e9383.

[119] Reumers, J.; Maurer-Stroh, S.; Schymkowitz, J.; Rousseau, F., Protein Sequences Encode Safeguards Against Aggregation. Human Mutation 2009, 30 (3), 431-437.

[120] Buell, A. K.; Tartaglia, G. G.; Birkett, N. R.; Waudby, C. A.; Vendruscolo, M.; Salvatella, X.; Welland, M. E.; Dobson, C. M.; Knowles, T. P. J., Position-Dependent Electrostatic Protection against Protein Aggregation. Chembiochem 2009, 10 (8), 13091312.

[121] Silow, M.; Oliveberg, M., Transient aggregates in protein folding are easily mistaken for folding intermediates. Proc Natl Acad Sci U $S A$ 1997, 94 (12), 6084-6.

[122] Otzen, D. E.; Kristensen, O.; Oliveberg, M., Designed protein tetramer zipped together with a hydrophobic Alzheimer homology: a structural clue to amyloid assembly. Proc Natl Acad Sci U S A 2000, 97 (18), 9907-12.

[123] Matysiak, S.; Clementi, C., Minimalist protein model as a diagnostic tool for misfolding and aggregation. Journal of Molecular Biology 2006, 363 (1), 297-308.

[124] Abeln, S.; Frenkel, D., Disordered flanks prevent peptide aggre gation. PLoS Comput Biol 2008, 4 (12), e1000241.

[125] Parrini, C.; Taddei, N.; Ramazzotti, M.; Degl'Innocenti, D.; Ramponi, G.; Dobson, C. M.; Chiti, F., Glycine residues appear to be evolutionarily conserved for their ability to inhibit aggregation. Structure (Camb) 2005, 13 (8), 1143-51.

[126] Gerling, U. I.; Brandenburg, E.; von Berlepsch, H.; Pagel, K.; Koksch, B., Structure analysis of an amyloid-forming model peptide by a systematic glycine and proline scan. Biomacro molecules 2011, 12 (8), 2988-96.

[127] Tartaglia, G. G.; Caflisch, A., Computational analysis of the S. cerevisiae proteome reveals the function and cellular localization of the least and most amyloidogenic proteins. Proteins 2007, 68 (1), 273-8.

[128] Chen, Y. W.; Dokholyan, N. V., Natural selection against protein aggregation on self-interacting and essential proteins in yeast, fly, and worm. Molecular Biology and Evolution 2008, 25 (8), 15301533.

[129] Wang, X.; Zhou, Y.; Ren, J. J.; Hammer, N. D.; Chapman, M. R., Gatekeeper residues in the major curlin subunit modulate bacterial amyloid fiber biogenesis. Proc Natl Acad Sci U S A 2010, 107 (1), 163-8.

[130] Sarkar, A.; Kumar, S.; Grover, A.; Sundar, D., Protein Aggregation in Neurodegenerative Diseases: Insights from Computational Analyses. Current Bioinformatics 2012, 7 (1), 87-95.

[131] Kurnik, M.; Hedberg, L.; Danielsson, J.; Oliveberg, M., Folding without charges. Proceedings of the National Academy of Sciences 2012, 109 (15), 5705-5710.

[132] Van Durme, J.; Maurer-Stroh, S.; Gallardo, R.; Wilkinson, H.; Rousseau, F.; Schymkowitz, J., Accurate Prediction of DnaKPeptide Binding via Homology Modelling and Experimental Data. Plos Computational Biology 2009, 5 (8).

[133] Tartaglia, G. G.; Pechmann, S.; Dobson, C. M.; Vendruscolo, M., Life on the edge: a link between gene expression levels and aggregation rates of human proteins. Trends in Biochemical Sciences 2007, 32 (5), 204-206.

[134] Castillo, V.; Grana-Montes, R.; Ventura, S., The aggregation properties of Escherichia coli proteins associated with their cellular abundance. Biotechnol J 2011, 6 (6), 752-60.

[135] Thangakani, A. M.; Kumar, S.; Velmurugan, D.; Gromiha, M. S. M., How do thermophilic proteins resist aggregation? ProteinsStructure Function and Bioinformatics 2012, 80 (4), 1003-1015.

[136] Kumar, S.; Singh, S. K.; Wang, X. L.; Rup, B.; Gill, D., Coupling of Aggregation and Immunogenicity in Biotherapeutics: T- and BCell Immune Epitopes May Contain Aggregation-Prone Regions. Pharmaceutical Research 2011, 28 (5), 949-961.

[137] Castillo, V.; Ventura, S., Amyloidogenic Regions and Interaction Surfaces Overlap in Globular Proteins Related to Conformational Diseases. Plos Computational Biology 2009, 5 (8).

[138] Masino, L.; Nicastro, G.; Calder, L.; Vendruscolo, M.; Pastore, A., Functional interactions as a survival strategy against abnormal aggregation. Faseb Journal 2011, 25 (1), 45-54.

[139] Lopez de la Paz, M.; Serrano, L., Sequence determinants of amyloid fibril formation. Proc Natl Acad Sci U S A 2004, 101 (1), 87-92.

[140] Tartaglia, G. G.; Cavalli, A.; Pellarin, R.; Caflisch, A., Prediction of aggregation rate and aggregation-prone segments in polypeptide sequences. Protein Science 2005, 14 (10), 2723-2734.

[141] Conchillo-Sole, O.; de Groot, N. S.; Aviles, F. X.; Vendrell, J.; Daura, X.; Ventura, S., AGGRESCAN: a server for the prediction and evaluation of "hot spots" of aggregation in polypeptides. Bmc Bioinformatics 2007, 8 .

[142] Trovato, A.; Seno, F.; Tosatto, S. C. E., The PASTA server for protein aggregation prediction. Protein Engineering Design \& Selection 2007, 20 (10), 521-523.

[143] Bryan, A. W.; Menke, M.; Cowen, L. J.; Lindquist, S. L.; Berger, B., BETASCAN: Probable beta-amyloids Identified by Pairwise Probabilistic Analysis. Plos Computational Biology 2009, 5 (3).

[144] Frousios, K. K.; Iconomidou, V. A.; Karletidi, C. M.; Hamodrakas, S. J., Amyloidogenic determinants are usually not buried. Bmc Structural Biology 2009, 9.

[145] Garbuzynskiy, S. O.; Lobanov, M. Y.; Galzitskaya, O. V. FoldAmyloid: a method of prediction of amyloidogenic regions from protein sequence. Bioinformatics 2010, 26 (3), 326-332. 